\title{
Impact of chronic obstructive pulmonary diseases on left ventricular diastolic function in hospitalized elderly patients
}

\author{
Ying-Shuo Huang \\ Ying-Chao Feng \\ Jian Zhang \\ Li Bai \\ Wei Huang \\ Min Li \\ Ying Sun
}

Department of Geriatrics and Gerontology, Beijing Friendship Hospital, Capital Medical University, Beijing, People's Republic of China

Correspondence: Ying Sun Department of Geriatrics and Gerontology, Beijing Friendship Hospital, Capital Medical University, No 95 Yong'An Road, XiCheng District, Beijing 100050, People's Republic of China Tel +8610 63137595

Email yingsun15@।63.com
This article was published in the following Dove Press journal:

Clinical Interventions in Aging

19 December 2014

Number of times this article has been viewed

Objective: To evaluate the impact of chronic obstructive pulmonary disease (COPD) on left ventricular (LV) diastolic function in hospitalized elderly patients.

Methods: This was a case-control observational study of 148 consecutive hospitalized elderly patients ( $\geq 65$ years old): 73 subjects without COPD as controls and 75 patients with COPD. Mildto-moderate COPD was defined as stages 1 and 2, while severe and very severe COPD was defined as stages 3 and 4, according to the Global Initiative for Chronic Obstructive Lung Disease guidelines. Clinical characteristics and echocardiographic parameters were analyzed and compared.

Results: Compared with the control group, patients with COPD had a higher frequency of LV diastolic dysfunction and heart failure with preserved ejection fraction. Smoking frequency, frequency of cerebrovascular diseases and diabetes, and serum N-terminal pro-B-type natriuretic peptide (NT-proBNP) levels were higher in the COPD group (all $P<0.05$ ). COPD patients showed more abnormalities in diastolic function ( $\left.E / e^{\prime}: 11.51 \pm 2.50 \mathrm{vs} 10.42 \pm 3.25, P=0.047\right)$, but no differences in systolic function and right ventricular function (all $P>0.05$ ). Patients with severe/very severe COPD showed no differences in LV diastolic function compared to patients with mild/moderate COPD $(P>0.05)$, but serum NT-proBNP levels were higher in severe/very severe COPD $(P<0.05)$.

Conclusion: Results suggest that early-stage COPD may have an impact on the LV diastolic function. Severe COPD mainly affected right ventricular function. In hospitalized elderly patients with COPD, LV diastolic dysfunction should be taken into account together with right ventricular function.

Keywords: chronic obstructive pulmonary disease, heart failure, left ventricular diastolic dysfunction, elderly, echocardiography

\section{Introduction}

Chronic obstructive pulmonary disease (COPD) is a major cause of morbidity and mortality in the world. COPD causes significant extrapulmonary effects and is associated with comorbidities that could contribute to the severity of the disease and prognosis. The co-existence of COPD and heart failure has been previously described. Population-based studies suggested that COPD increases the risk of cardiovascular morbidity and mortality by $\sim 2$-fold. ${ }^{1}$ Another study showed that the risk of developing congestive heart failure was 4.5-fold greater in elderly patients with COPD compared with age-matched controls. ${ }^{2}$ Left ventricular (LV) diastolic dysfunction (LVDD) has been reported in COPD patients, ${ }^{3}$ but the relationship between COPD and LVDD or heart failure with preserved ejection fraction (HFpEF) is less well understood.

We hypothesized that COPD has an impact on the frequency of LVDD and HFpEF. The aim of the present study was to evaluate the impact of COPD on LV diastolic function in hospitalized elderly patients. 


\section{Methods}

\section{Participants}

This was a case-control observational study of consecutive patients hospitalized at the Department of Geriatrics and Gerontology between December 2011 and December 2013. Seventy-five patients with COPD were enrolled, as well as 73 subjects without COPD as controls. The diagnosis of COPD was made according to the guidelines of the Global Initiative for Chronic Obstructive Lung Disease (GOLD) criteria. ${ }^{4}$ In the COPD group, 49 patients showed mild-tomoderate pulmonary function (GOLD stages 1 and 2) and 26 patients showed severe-to-very severe pulmonary function (GOLD stages 3 and 4).

Exclusion criteria were the following: 1) COPD patients during acute exacerbation period; 2) patients with asthma, hypoxia, or pneumonia; 3) patients with LV systolic dysfunction (LVSD), valvular pathology, or arrhythmia; 4) patients with renal failure; 5) patients with diffuse parenchymal lung diseases, lung carcinoma, or other malignancies; or 6) age $<65$ years.

The ethics committee of the hospital approved the study protocol. Subjects provided a written informed consent.

\section{Baseline characteristics}

A detailed medical history was obtained from each subject. Comorbidities included cardiovascular disease (CVD), hypertension, diabetes mellitus, cerebrovascular diseases, and chronic kidney disease (CKD). Additional demographics data included age, sex, smoking status, height, and weight. Body mass index was calculated as weight $(\mathrm{kg}) /$ height $\left(\mathrm{m}^{2}\right)$.

\section{Pulmonary function tests}

Pulmonary function tests (PFTs) were performed using a clinical spirometer (SensoMedics, the Netherlands). Spirometry was performed by a trained technician according to the American Thoracic Society/European Respiratory Society guidelines. ${ }^{5}$ Forced expiratory volume in 1 second $\left(\mathrm{FEV}_{1}\right)$ and forced vital capacity values were obtained, and the $\mathrm{FEV}_{1}$ / forced vital capacity ratio was calculated. PFT results were evaluated according to the guidelines. ${ }^{5}$ All patients were diagnosed using spirometry.

\section{Echocardiography}

Echocardiography was performed using an ultrasound system (Vivid 7; GE Healthcare, Waukesha, WI, USA). Results were analyzed by an echo-cardiologist blinded to all clinical data. Measurements were done at least twice by the same operator. Analyzed images included two-dimensional views from the parasternal long axis and mid-ventricular short axis, and two- and four-chamber views. Left ventricle wall thickness, LV end-diastolic and end-systolic diameters, right ventricle diameter, and left atrium areas were measured. LV ejection fraction (LVEF) was calculated from LV systolic and diastolic volumes using the Simpson's method using two-dimensional echocardiography. Parameters obtained from Doppler analysis were peak flow velocity of early diastolic filling (E wave), peak flow velocity of late atrial filling (A wave), and septal and lateral annular tissue Doppler velocities (septal and lateral $e^{\prime}$ ). All parameters were measured according to the recommendations of the American Society of Echocardiography. ${ }^{6}$

HFpEF was diagnosed using the following criteria (2012 ESC Guidelines of Heart Failure Management) ${ }^{7}$ : 1) typical symptoms of heart failure including breathlessness, orthopnea, paroxysmal nocturnal dyspnea, reduced exercise tolerance, fatigue, tiredness, increased time to recover after exercise, and ankle swelling; 2) typical signs of heart failure, such as elevated jugular venous pressure, hepatojugular reflux, third heart sound (gallop rhythm), laterally displaced apical impulse, and cardiac murmur; 3) normal or only mildly reduced LVEF with no evidence of LV dilation; and 4) relevant structural heart disease (LV hypertrophy/left atrial enlargement) and/or diastolic dysfunction.

\section{NT-proBNP}

Blood samples were drawn in tubes containing ethylenediaminetetraacetic acid and were analyzed the same day. After centrifugation, serum and plasma samples were stored at $-70^{\circ} \mathrm{C}$. N-terminal pro-B-type natriuretic peptide (NTproBNP) was measured with electrochemiluminescence immunoassay using an Elecsys 2010 system (Roche Diagnostics, Basel, Switzerland). NT-proBNP concentrations are presented as picograms per milliliter.

\section{Statistical analysis}

Continuous variables are expressed as mean \pm standard deviation, and were compared using the Student's $t$-test. Categorical variables are presented as frequency, and were analyzed using the chi-square test. Independent predictors of COPD were analyzed by binary logistic models using backward stepwise regression analysis. Analysis was performed using SPSS 15.0 (SPSS Inc., Chicago, IL, USA). $P$-values $<0.05$ were considered statistically significant.

\section{Results}

\section{Baseline characteristics}

Demographic data are presented in Table 1. Most patients were men $(n=111,75 \%)$, and the mean age was $80.74 \pm 6.75$ years. 
Patients with COPD were older $(P=0.027)$ and included more smokers $(P=0.009)$. There was a higher frequency of cerebrovascular diseases, diabetes mellitus, beta-blockers treatment, and diuretics treatment in the COPD group (all $P<0.05)$. There was no significant difference in terms of body mass index, hypertension, CVD, and CKD between the COPD and control groups.

Levels of NT-proBNP were higher in patients with COPD (372.65 \pm 651.97 vs $218.76 \pm 368.80 \mathrm{pg} / \mathrm{mL}, P=0.01$ ). Levels of triglycerides, serum albumin, and high-density lipoprotein cholesterol were all lower in the COPD group (all $P<0.05$ ) (Table 1).

\section{Echocardiographic characteristics}

Echocardiographic characteristics are presented in Table 2. Compared with the control group, the $E / e^{\prime}$ ratio was significantly higher in the COPD group (11.51 \pm 2.50 vs $10.42 \pm 3.25$,
$P=0.047)$. No difference was observed in the other echocardiographic parameters (LV structural parameters, right ventricular diastolic diameter, or systolic pulmonary artery pressure of the two groups).

\section{Distribution of COPD stages and frequency of LVDD and HFpEF}

In the COPD group, the proportion of patients with stages $1-4$ COPD was $6.7 \%, 58.7 \%, 30.7 \%$, and $4.0 \%$, respectively. In the present study, $65.4 \%$ of patients had mild/moderate COPD and $34.7 \%$ had severe/very severe COPD.

In the control group, 28 patients (38.4\%) suffered from LVDD and 19 (26.0\%) from symptomatic heart failure (NYHA II-IV stage). Among COPD patients, LVDD and symptomatic heart failure were present in $48 / 75(64.0 \%)$ and $38 / 75(50.7 \%)$ of patients, respectively $(P<0.05)$.

Table I Baseline characteristics of patients in the control and COPD groups

\begin{tabular}{|c|c|c|c|c|}
\hline Baseline characteristics & $\begin{array}{l}\text { Control group, } \\
\mathrm{N}=73\end{array}$ & $\begin{array}{l}\text { COPD group, } \\
\mathrm{N}=75\end{array}$ & $\begin{array}{l}\text { Mild/moderate } \\
\text { COPD, } \mathrm{N}=49\end{array}$ & $\begin{array}{l}\text { Severe/very severe } \\
\text { COPD, } \mathrm{N}=\mathbf{2 6}\end{array}$ \\
\hline \multicolumn{5}{|l|}{ Demographics } \\
\hline Age (years), mean \pm SD & $78.67 \pm 7.14$ & $82.76 \pm 5.7 I^{\mathrm{a}}$ & $82.02 \pm 6.02$ & $84.15 \pm 4.89$ \\
\hline Male, $n(\%)$ & $51(69.9)$ & $60(80.0)$ & $38(77.6)$ & $22(84.6)$ \\
\hline BMI $\left(\mathrm{kg} / \mathrm{m}^{2}\right)$, mean $\pm \mathrm{SD}$ & $23.92 \pm 3.10$ & $23.56 \pm 3.10$ & $24.01 \pm 3.12$ & $22.72 \pm 2.95$ \\
\hline Smokers, n (\%) & $20(27.4)$ & $44(58.7)^{\mathrm{a}}$ & $25(51.0)$ & $19(73.1)$ \\
\hline \multicolumn{5}{|l|}{ Medical history, n (\%) } \\
\hline Hypertension & $4 \mid(56.2)$ & $52(69.3)$ & $40(81.6)$ & $12(46.2)^{\mathrm{b}}$ \\
\hline Cardiovascular diseases & $32(43.8)$ & $29(38.7)$ & $21(42.9)$ & $8(30.8)$ \\
\hline Cerebrovascular diseases & $39(53.4)$ & $52(69.3)^{\mathrm{a}}$ & $32(65.3)$ & $20(76.9)$ \\
\hline Diabetes mellitus & $27(36.9)$ & $17(45.4)^{\mathrm{a}}$ & $26(53.1)$ & $8(30.8)$ \\
\hline Chronic kidney diseases & $12(16.4)$ & $14(18.7)$ & $12(24.5)$ & $5(19.2)$ \\
\hline \multicolumn{5}{|l|}{ Medication, n (\%) } \\
\hline Beta-blockers & $12(16.4)$ & $32(42.7)^{\mathrm{a}}$ & $18(36.7)$ & I4 (53.8) \\
\hline Aspirin & $28(38.4)$ & $32(42.7)$ & $23(46.9)$ & $14(53.8)$ \\
\hline Diuretics & 0 & $33(44.0)^{\mathrm{a}}$ & $22(44.9)$ & II (42.3) \\
\hline ACE inhibitors/ARBs & $23(31.5)$ & $33(44.0)$ & $22(44.9)$ & II (42.3) \\
\hline Statin & $31(42.5)$ & $35(46.7)$ & $23(46.9)$ & $12(46.2)$ \\
\hline \multicolumn{5}{|l|}{ Biochemistry, mean \pm SD } \\
\hline NT-proBNP (pg/mL) & $218.76 \pm 368.80$ & $372.65 \pm 651.97^{\mathrm{a}}$ & $264.22 \pm 98.85$ & $467.80 \pm 767.82^{\mathrm{b}}$ \\
\hline Oxygen saturation (\%) & $96.73 \pm 1.74$ & $94.15 \pm 2.47^{\mathrm{a}}$ & $94.53 \pm 2.52$ & $93.42 \pm 2.25$ \\
\hline $\operatorname{TnT}(\mu g / L)$ & $0.021 \pm 0.015$ & $0.022 \pm 0.019$ & $0.022 \pm 0.019$ & $0.021 \pm 0.020$ \\
\hline $\mathrm{SCr}(\mu \mathrm{mol} / \mathrm{L})$ & $84.77 \pm 45.53$ & $98.99 \pm 48.20$ & $99.08 \pm 45.81$ & $98.82 \pm 53.36$ \\
\hline Serum albumin $(g / d L)$ & $3.82 \pm 0.42$ & $3.79 \pm 0.3 \mathrm{I}^{\mathrm{a}}$ & $3.8 I \pm 0.3 I$ & $3.76 \pm 0.31$ \\
\hline Total cholesterol (mmol/L) & $4.40 \pm 1.08$ & $4.35 \pm 0.90$ & $4.37 \pm 0.92$ & $4.30 \pm 0.88$ \\
\hline Triglycerides (mmol/L) & $1.39 \pm 0.86$ & $1.13 \pm 0.55^{\mathrm{a}}$ & $4.37 \pm 0.92$ & $4.30 \pm 0.88^{b}$ \\
\hline High-density lipoprotein cholesterol (mmol/L) & $1.27 \pm 0.45$ & $1.21 \pm 0.30^{\mathrm{a}}$ & $1 .|2 \pm 0.4|$ & $1.16 \pm 0.77$ \\
\hline Low-density lipoprotein cholesterol (mmol/L) & $2.55 \pm 0.89$ & $2.6 I \pm 0.70$ & $2.60 \pm 0.74$ & $2.63 \pm 0.65$ \\
\hline Leukocytes $\left(\times 10^{9} / \mathrm{L}\right)$ & $6.35 \pm 2.76$ & $6.77 \pm 2.27$ & $6.50 \pm 2.24$ & $7.27 \pm 2.27$ \\
\hline Hemoglobin (g/dL) & $12.78 \pm 1.60$ & $|2.53 \pm 1.8|$ & $126.79 \pm 17.20$ & $122.59 \pm 19.73$ \\
\hline Platelets ( $\left.\times 10^{9} / \mathrm{L}\right)$ & $210.31 \pm 131.16$ & $192.01 \pm 74.67$ & $190.62 \pm 67.73$ & $194.58 \pm 87.44$ \\
\hline
\end{tabular}

Notes: ${ }^{\mathrm{P}}<0.05$ between the control and COPD groups. ${ }^{\mathrm{b}} \mathrm{P}<0.05$ between the mild/moderate and severe/very severe COPD groups.

Abbreviations: ACE, angiotensin-converting enzyme; ARBs, angiotensin receptor blockers; BMI, body mass index; COPD, chronic obstructive pulmonary disease; NT-proBNP, N-terminal pro-B-type natriuretic peptide; SCr, serum creatinine; SD, standard deviation; TnT, troponin T. 
Table 2 Echocardiographic characteristics of patients in the control and in COPD groups

\begin{tabular}{|c|c|c|c|c|}
\hline Characteristics & $\begin{array}{l}\text { Control group, } \\
N=73\end{array}$ & $\begin{array}{l}\text { COPD group, } \\
N=75\end{array}$ & $\begin{array}{l}\text { Mild/moderate } \\
\text { COPD, } \mathrm{N}=49\end{array}$ & $\begin{array}{l}\text { Severe/very severe } \\
\text { COPD, } \mathrm{N}=26\end{array}$ \\
\hline Ascending aorta diameter $(\mathrm{mm})$ & $35.03 \pm 3.06$ & $34.93 \pm 3.62$ & $35.27 \pm 3.64$ & $34.31 \pm 3.58$ \\
\hline $\mathrm{LA}(\mathrm{mm})$ & $35.11 \pm 3.73$ & $37.08 \pm 2.82^{\mathrm{a}}$ & $37.31 \pm 3.05$ & $36.88 \pm 2.25$ \\
\hline LVED (mm) & $47.5 I \pm 2.77$ & $47.15 \pm 2.83$ & $47.47 \pm 2.79$ & $46.54 \pm 2.86$ \\
\hline LVES (mm) & $29.95 \pm 2.69$ & $30.76 \pm 3.66$ & $30.76 \pm 3.59$ & $30.77 \pm 3.87$ \\
\hline LVEF (\%) & $66.67 \pm 4.36$ & $64.4 I \pm 7.22$ & $64.73 \pm 6.83$ & $63.8 \mathrm{I} \pm 8.00$ \\
\hline Left ventricular septal thickness (mm) & $10.03 \pm 0.94$ & $10.17 \pm 1.12$ & $10.22 \pm 1.05$ & $10.08 \pm 1.26$ \\
\hline Left ventricular posterior wall thickness $(\mathrm{mm})$ & $9.69 \pm 0.84$ & $9.84 \pm 0.84$ & $9.82 \pm 0.83$ & $9.88 \pm 0.86$ \\
\hline$E$ & $63.21 \pm 14.10$ & $63.79 \pm 12.05$ & $65.27 \pm 12.15$ & $61.00 \pm 11.59$ \\
\hline$A$ & $91.40 \pm 17.17$ & $92.69 \pm 16.39$ & $95.45 \pm 15.879$ & $87.50 \pm 16.38$ \\
\hline E/A ratio & $0.70 \pm 0.16$ & $0.70 \pm 0.13$ & $0.69 \pm 0.13$ & $0.7 I \pm 0.14$ \\
\hline $\mathrm{e}^{\prime}$ & $6.31 \pm 1.36$ & $6.23 \pm 1.22$ & $6.28 \pm 1.10$ & $6.15 \pm 1.43$ \\
\hline$E / e^{\prime}$ ratio & $10.42 \pm 3.25$ & $11.51 \pm 2.50^{\mathrm{a}}$ & $|I .59 \pm 2.4|$ & $11.37 \pm 2.70$ \\
\hline Right ventricular diastolic diameter $(\mathrm{mm})$ & $12.40 \pm 3.78$ & $11.83 \pm 6.77$ & $10.73 \pm 3.16$ & $13.88 \pm 10.48$ \\
\hline Main pulmonary artery diameter & $21.88 \pm 1.26$ & $22.03 \pm 2.11$ & $22.27 \pm 2.4 I$ & $21.58 \pm 1.33$ \\
\hline Tricuspid regurgitation velocity $(\mathrm{m} / \mathrm{s})$ & $224.42 \pm 23.38$ & $238.91 \pm 28.76$ & $239.76 \pm 27.72$ & $237.35 \pm 31.16$ \\
\hline $\mathrm{sPAP}(\mathrm{mmHg})$ & $19.78 \pm 9.81$ & $25.11 \pm 9.50$ & $24.99 \pm 9.59$ & $25.33 \pm 9.49$ \\
\hline
\end{tabular}

Note: ${ }^{a}<0.05$ between the control and COPD groups.

Abbreviations: $A$, peak late mitral flow velocity; COPD, chronic obstructive pulmonary disease; $E$, peak early mitral flow velocity; $\mathrm{e}^{\prime}$, velocity of mitral annulus early diastolic motion; E/A ratio, ratio of early $(E)$ to late $(A)$ mitral flow peak velocities; E/e', left ventricular filling index; LA, left atrium diameter; LVED, left ventricular end-diastolic diameter; LVEF, left ventricular ejection fraction; LVES, Left ventricular end-systolic diameter; sPAP, systolic pulmonary artery pressure.

\section{Differences between mild/moderate and severe/very severe COPD}

Patients with severe/very severe COPD had significantly higher levels of NT-proBNP and had a tendency toward a higher frequency of abnormal right ventricular diastolic diameter and systolic pulmonary artery pressure $(P=0.078$ and $P=0.064$, respectively). There was no difference in LV diastolic function parameters between patients with different stages of COPD (Tables 1 and 2).

\section{Severity of COPD and cardiovascular function}

Binary logistic models showed that age (odds ratio $[\mathrm{OR}]=1.081,95 \%$ confidence interval $[95 \% \mathrm{CI}]=1.000-1.169$, $P=0.05)$ and smoking $(\mathrm{OR}=1.061,95 \% \mathrm{CI}=1.005-1.121$, $P=0.03$ ) were independent predictors of COPD (Table 3).

\section{Discussion}

The main finding of the present study was that there was a high frequency of LVDD in elderly patients with COPD, and that LVDD may occur in the early stages of COPD.

\section{Comorbidities of COPD}

Several comorbidities are associated with COPD. In an 11-year observational retrospective study (PATHOS) of 21,361 COPD patients (mean age of 68.0 years, $53 \%$ females $),{ }^{8}$ the most common comorbidities were hypertension (33.7\%), heart failure (15.2\%), ischemic heart disease (15.6\%), and diabetes (11.6\%). In the present study, the frequency of hypertension, CVD, and diabetes was much higher $(69.3 \%, 38.7 \%$, and $45.4 \%$, respectively). It is well known that the frequency of hypertension, CVD, and diabetes increases substantially with age, and the mean age of the participants of the present study was $80.74 \pm 6.75$ years, much older than the previous study. ${ }^{8}$ In addition, the present study was performed in hospitalized patients, which was different from this previous study.

\section{Frequency of LVDD in COPD}

The present study observed a high frequency of LVDD in patients with COPD (65.6\%), but there was no difference among different stages of COPD. In agreement with these results, Boussuges et al found a high frequency of LVDD in patients with $\operatorname{COPD}(76 \%) .{ }^{3}$ Funk et al also reported a prevalence rate of more than $50 \% .^{9}$ A recent study ${ }^{10}$ showed more frequent echocardiographic findings of mild LVDD (88\%) in COPD patients, independently of COPD stage. Another

Table 3 Multivariate analysis of the predictors of COPD

\begin{tabular}{lll}
\hline Variable & OR (95\% CI) & $P$-values \\
\hline Age & $1.08 I(1.000-1.169)$ & 0.05 \\
Smoking & $1.061(1.005-1.121)$ & 0.033 \\
Left atrium diameter & $1.132(0.980-1.307)$ & 0.091 \\
\hline
\end{tabular}

Abbreviations: COPD, chronic obstructive pulmonary disease; $\mathrm{Cl}$, confidence interval; OR, odds ratio. 
study ${ }^{11}$ focused on outpatients with severe COPD $\left(\mathrm{FEV}_{1}\right.$ of $30 \%-50 \%$ ), and showed a potentially highest prevalence of LVDD (90\%) in patients with severe stable COPD. Therefore, the difference in the frequency of LVDD in patients with COPD between the present and previous studies might be due to different distribution of COPD stages, age, sex, and comorbidities. In addition, a recent study ${ }^{12}$ showed diastolic dysfunction in $47.5 \%$ of patients with COPD, and only $27.5 \%$ of their patients had severe/very severe COPD.

\section{Relationship between COPD and LVDD}

There is a well-known association between COPD and heart failure. In the last decade, prior studies mainly focused on the relationship between LVSD right ventricular dysfunction and COPD, but few studies evaluated LVDD and COPD. LVDD can be asymptomatic or associated with heart failure symptoms (eg, HFpEF). The incidence of HFpEF increases with age; hypertension, atrial fibrillation, diabetes mellitus, and female sex are the most common risk factors of HFpEF.? In the present study, approximately two-thirds of the patients had a diagnosis of hypertension. The left diastolic function changes with aging, and because our study was restricted to elderly patients, we had to consider changes in echocardiographic parameters that are associated with aging, ${ }^{13,14}$ such as reduced early diastolic filling and increased late diastolic filling.

The potential pathophysiologic mechanism for the association between COPD and LVDD and HFpEF could be systemic inflammation. Inflammation is considered to be one of the systemic manifestations of COPD. Indeed, inflammation can promote atherosclerotic plaque formation, which is associated with myocardial ischemia and LVDD. However, in the present study, leukocyte levels were not different between the control and COPD groups, and there was no correlation with severe stages of COPD. Therefore, these results suggest that there may be some other mechanisms involved in this process.

Furthermore, the presence of cor pulmonale secondary to pulmonary hypertension can lead to interventricular septum deviation toward the left ventricle, which could alter LV structure and delay filling compliance. ${ }^{15}$ This mechanism could explain why COPD severity was associated with worse diastolic function. In our study, the main significant differences in echocardiographic findings were the left atrium diameter (35.11 \pm 3.73 in controls and 37.08 \pm 2.82 in COPD) and the $E / e^{\prime}$ ratio $(10.42 \pm 3.25$ in controls and $11.51 \pm 2.50$ in COPD), but there was no difference in systolic pulmonary artery pressure. These results are supported by two previous studies,,${ }^{916}$ implying that even in the absence of right ventricular changes or pulmonary hypertension, LVDD may be already in place.

Besides the two possible mechanisms indicated earlier, LVDD in patients with COPD may be due to abnormal pathophysiological changes in LV preload and/or afterload. Thoracic cavity hyperinflation secondary to emphysema may impair LV filling (preload) and further affect LV diastolic function. ${ }^{17}$ In the meantime, a relationship between LV diastolic filling and emphysema has also been observed in patients with mild flow obstruction (without hyperinflation). ${ }^{16}$ This means that the pathogenic causes of impaired LV filling are likely to be multifactorial. The earlier return of reflected arterial wave can increase LV afterload, while the concomitant reduction of aortic diastolic blood pressure may lead to subendocardial ischemia. These effects can act together to affect myocardial relaxation. ${ }^{18}$

\section{COPD and NT-proBNP}

NT-proBNP is an important and helpful indicator in congestive heart failure. Elevated NT-proBNP levels have been found in patients with COPD. ${ }^{19}$ Moreover, increased NT-proBNP levels can be seen in diseases such as LVDD and right ventricular dysfunction secondary to pulmonary diseases without decreased LVEF. ${ }^{20}$ Therefore, measurement of NT-proBNP levels can be useful in the diagnosis of impaired right ventricular functions in patients with COPD and HFpEF.

In the present study, we found significant differences between patients with COPD and controls in terms of NTproBNP values. Serum NT-proBNP values were significantly higher in patients with COPD compared with controls $(372.65 \pm 651.97$ vs $218.76 \pm 368.80 \mathrm{pg} / \mathrm{mL})$. These results are supported by previous studies. ${ }^{21,22}$ Differences in NT-proBNP levels were in accordance with the differences of LVDD and HFpEF between the control and COPD groups. There was no difference in LVDD between the mild/moderate and severe/very severe COPD groups, but NT-proBNP levels remained significantly different. Therefore, results suggest that NT-proBNP levels increase with the severity of COPD and that the mechanisms for these changes may be independent from LVDD.

In the present study, logistic regression analysis showed that age and smoking were independent risk factors for COPD. Previous studies suggested that age and tobacco consumption were associated with COPD ${ }^{23-26}$ However, further studies are necessary to correctly identify and quantify the risk factors for COPD and LVDD. 


\section{Limitations}

The present study included a small sample size, which may lead to bias. In addition, patients were not followed up. All patients were hospitalized, which is not representative of the whole population of patients $>65$ years old. In addition, our database had missing data for some variables. Therefore, additional multicenter prospective studies with a larger number of patients are necessary before being able to generalize our findings.

\section{Conclusion}

There is a high frequency of LVDD in hospitalized patients with COPD, and LVDD may occur at the early stages of COPD, prior to changes in right ventricular function and pulmonary hypertension. In hospitalized elderly patients with COPD, LVDD should be taken into account besides right ventricular function. Closer co-operation between pulmonologists and cardiologists is necessary to optimize the management of this large population of patients.

\section{Acknowledgments}

This work was supported by the Basic and Clinical Research Cooperation Program of Capital Medical University (grant number 13JL48) and the Beijing Excellent Talents Training Program (grant number 2011D003034000026).

\section{Disclosure}

The authors report no conflicts of interest in this work.

\section{References}

1. Sin DD, Man SF. Why are patients with chronic obstructive pulmonary disease at increased risk of cardiovascular diseases? The potential role of systemic inflammation in chronic obstructive pulmonary disease. Circulation. 2003;107(11):1514-1519.

2. Curkendall SM, DeLuise C, Jones JK, et al. Cardiovascular disease in patients with chronic obstructive pulmonary disease, Saskatchewan Canada cardiovascular disease in COPD patients. Ann Epidemiol. 2006; 16(1):63-70.

3. Boussuges A, Pinet $C$, Molenat $F$, et al. Left atrial and ventricular filling in chronic obstructive pulmonary disease. An echocardiographic and Doppler study. Am J Respir Crit Care Med. 2000;162(2 pt 1):670-675.

4. Vestbo J, Hurd SS, Agustí AG, et al. Global strategy for the diagnosis, management, and prevention of chronic obstructive pulmonary disease: GOLD executive summary. Am J Respir Crit Care Med. 2013;187(4): 347-365.

5. Pellegrino R, Viegi G, Brusasco V, et al. Interpretative strategies for lung function tests. Eur Respir J. 2005;26(5):948-968.

6. Gottdiener JS, Bednarz J, Devereux R, et al. American Society of Echocardiography recommendations for use of echocardiography in clinical trials. J Am Soc Echocardiogr. 2004;17(10):1086-1119.

7. McMurray JJ, Adamopoulos S, Anker SD, et al. ESC guidelines for the diagnosis and treatment of acute and chronic heart failure 2012: The Task Force for the Diagnosis and Treatment of Acute and Chronic Heart Failure 2012 of the European Society of Cardiology. Developed in collaboration with the Heart Failure Association (HFA) of the ESC. Eur J Heart Fail. 2012;14(8):803-869.
8. Ställberg B, Janson C, Johansson G, et al. Management, morbidity and mortality of COPD during an 11-year period: an observational retrospective epidemiological register study in Sweden (PATHOS). Prim Care Respir J. 2014;23(1):38-45.

9. Funk GC, Lang I, Schenk P, Valipour A, Hartl S, Burghuber OC. Left ventricular diastolic dysfunction in patients with COPD in the presence and absence of elevated pulmonary arterial pressure. Chest. 2008;133(6): 1354-1359.

10. Caram LM, Ferrari R, Naves CR, et al. Association between left ventricular diastolic dysfunction and severity of chronic obstructive pulmonary disease. Clinics. 2013;68(6):772-776.

11. López-Sánchez M, Muñoz-Esquerre M, Huertas D, et al. High prevalence of left ventricle diastolic dysfunction in severe COPD associated with a low exercise capacity: a cross-sectional study. PLoS One. 2013; 8(6):e68034.

12. Gupta NK, Agrawal RK, Srivastav AB, Ved ML. Echocardiographic evaluation of heart in chronic obstructive pulmonary disease patient and its co-relation with the severity of disease. Lung India. 2011;28(2): 105-109.

13. Tighe DA, Vinch CS, Hill JC, Meyer TE, Goldberg RJ, Aurigemma GP. Influence of age on assessment of diastolic function by Doppler tissue imaging. Am J Cardiol. 2003;91(2):254-257.

14. Oxenham H, Sharpe N. Cardiovascular aging and heart failure. Eur $J$ Heart Fail. 2003;5(4):427-434.

15. Minai OA, Chaouat A, Adnot S. Pulmonary hypertension in COPD: epidemiology, significance, and management: pulmonary vascular disease: the global perspective. Chest. 2010;137(Suppl 6):39S-51S.

16. Barr RG, Bluemke DA, Ahmed FS, et al. Percent emphysema, airflow obstruction, and impaired left ventricular filling. N Engl J Med. 2010; 362(3):217-227.

17. Watz H, Waschki B, Meyer T, et al. Decreasing cardiac chamber sizes and associated heart dysfunction in COPD: role of hyperinflation. Chest. 2010;138(1):32-38.

18. Laurent S, Cockcroft J, Van Bortel L, et al; European Network for Noninvasive Investigation of Large Arteries. Expert consensus document on arterial stiffness: methodological issues and clinical applications. Eur Heart J. 2006;27(21):2588-2605.

19. Yap LB, Mukerjee D, Timms PM, Ashrafian H, Coghlan JG. Natriuretic peptides, respiratory disease, and the right heart. Chest. 2004;126(4): $1330-1336$.

20. Tsai SH, Lin YY, Chu SJ, Hsu CW, Cheng SM. Interpretation and use of natriuretic peptides in non-congestive heart failure settings. Yonsei Med J. 2010;51(2):151-163.

21. Chi SY, Kim EY, Ban HJ, et al. Plasma N-terminal pro-brain natriuretic peptide: a prognostic marker in patients with chronic obstructive pulmonary disease. Lung. 2012;190(3):271-276.

22. Bozkanat E, Tozkoparan E, Baysan O, Deniz O, Ciftci F, Yokusoglu M. The significance of elevated brain natriuretic peptide levels in chronic obstructive pulmonary disease. J Int Med Res. 2005;33(5):537-544.

23. Antonelli-Incalzi R, Imperiale C, Bellia V, et al. Do GOLD stages of COPD severity really correspond to differences in health status? Eur Respir J. 2003;22(3):444-449.

24. Feary JR, Rodrigues LC, Smith CJ, Hubbard RB, Gibson JE. Prevalence of major comorbidities in subjects with COPD and incidence of myocardial infarction and stroke: a comprehensive analysis using data from primary care. Thorax. 2010;65(11):956-962.

25. Lindberg A, Jonsson AC, Ronmark E, Lundgren R, Larsson LG, Lundback B. Ten-year cumulative incidence of COPD and risk factors for incident disease in a symptomatic cohort. Chest. 2005;127(5): $1544-1552$

26. Fukuchi $Y$, Nishimura M, Ichinose M, et al. COPD in Japan: the Nippon COPD Epidemiology study. Respirology. 2004;9(4):458-465. 


\section{Publish your work in this journal}

Clinical Interventions in Aging is an international, peer-reviewed journal focusing on evidence-based reports on the value or lack thereof of treatments intended to prevent or delay the onset of maladaptive correlates of aging in human beings. This journal is indexed on PubMed Central, MedLine,
Dovepress

CAS, Scopus and the Elsevier Bibliographic databases. The manuscript management system is completely online and includes a very quick and fair peer-review system, which is all easy to use. Visit http://www.dovepress. $\mathrm{com} /$ testimonials.php to read real quotes from published authors. 